\title{
The Economic Impacts of Open Science: A Rapid Evidence Assessment
}

\author{
Michael J. Fell \\ UCL Energy Institute, University College London, London WC1H 0NN, UK; michael.fell@ucl.ac.uk
}

Received: 24 May 2019; Accepted: 26 June 2019; Published: 1 July 2019

check for updates

\begin{abstract}
A common motivation for increasing open access to research findings and data is the potential to create economic benefits-but evidence is patchy and diverse. This study systematically reviewed the evidence on what kinds of economic impacts (positive and negative) open science can have, how these comes about, and how benefits could be maximized. Use of open science outputs often leaves no obvious trace, so most evidence of impacts is based on interviews, surveys, inference based on existing costs, and modelling approaches. There is indicative evidence that open access to findings/data can lead to savings in access costs, labour costs and transaction costs. There are examples of open science enabling new products, services, companies, research and collaborations. Modelling studies suggest higher returns to $R \& D$ if open access permits greater accessibility and efficiency of use of findings. Barriers include lack of skills capacity in search, interpretation and text mining, and lack of clarity around where benefits accrue. There are also contextual considerations around who benefits most from open science (e.g., sectors, small vs. larger companies, types of dataset). Recommendations captured in the review include more research, monitoring and evaluation (including developing metrics), promoting benefits, capacity building and making outputs more audience-friendly.
\end{abstract}

Keywords: open science; open access; open data; economic impacts

\section{Introduction}

There has been a trend towards increasing openness in research practices in the United Kingdom (UK) and internationally. There is now an expectation that, except under certain circumstances, UK Research Council funded research will be published in open access format and that underlying data will be freely shared [1,2]. The European Union has an extensive programme of work on open science, including a declaration of open science principles [3] and a monitoring programme [4]. In the United States, the Fair Access to Science and Technology Research Act requires publicly funded scientific research to be made freely accessible online [5]. Open practices are expected to bring 'significant social and economic benefits' ([1], p1), among other benefits [6]. However, while previous reviews have touched on this topic $[7,8]$, no systematic attempt has yet been made to identify and synthesize evidence relating to this claim and present a clear picture of the economic impacts that open science might have, how these comes about, and how benefits might be maximized.

The aim of this rapid evidence assessment (REA) is to bring together the best available evidence to answer the question: What are the economic impacts of open science? It has the following specific objectives:

- To identify the types of direct and indirect economic impact that open science has been empirically demonstrated to have.

- To identify the mechanisms by which economic impacts come about.

- To identify the contextual factors that affect whether or not (and the extent to which) economic impacts occur, and the extent to which the open science approach was a necessary condition of their occurring. 
- To assess the magnitude and relative importance of different types of impact (positive and negative).

- To identify methods by which economic impacts have been (or have been suggested to be) recorded and/or quantified, and how counterfactuals (i.e., non-open science approaches) have been estimated.

- To identify policies (or other interventions including [but not limited to] clearer/better communications about knowledge exchange and open science) which can help maximize the economic benefits and reduce the costs associated with open science.

- To identify trade-offs between economic and other (e.g., academic, societal) impacts.

The term 'open science' has a broad range of meanings, ranging from the publishing of research outputs (rather than keeping them confidential) to free sharing of every aspect of research including protocols, analysis plans and notebooks [9]. Key elements are transparency, accessibility, sharing and collaboration [10]. The scope of this rapid review if restricted to open access to research findings (usually through open access publishing) and data (open research data), since these are the most mature areas where there is likely to be the most evidence, and where funders' requirements are currently most explicit. Hereafter in this paper, I use the term 'open science' to refer to these concepts-but it is important to bear in mind that the review does not capture all impacts that might be associated with employing the full suite of open science practices.

The review takes in direct economic impacts in which open science has been a contributory factor, including changes in productivity, competitiveness, employment, income, investment, and value. The focus was on impacts in the economy in general, not those restricted only to the ecosystem around scholarly communication (e.g., publishers, university library budgets, etc.), since the latter topic has been widely considered in the context of the debate around transition to open access publishing. Indirect benefits—such as increases in economic productivity through health improvements resulting from new drugs developed with the contribution of open science outputs-are recognized as potentially very important, but are out of scope. It is important to emphasize that economic impacts are certainly not the only, or necessarily the most significant, area where open science has to the potential to make a positive (or negative) contribution-access to knowledge and data has intrinsic and extrinsic benefits that go well beyond this-but these impacts are also not considered in this review.

Before moving on, it is important to say a little more about the existing reviews, mentioned above, which have touched on the question of economic impacts. These useful documents consider a broad range of impacts associated with open science/access. But due to this breadth of coverage, they are able to dedicate limited attention specifically to economic impacts. Study [7] by ElSabry focuses on societal impacts in general, such as the use of research findings by policymakers and practitioners. While it includes some mention of economic questions, they are not given explicit or focused consideration. While basic methodological details of the review are provided it is not possible to tell how studies were identified or data extracted. Study [8], by Tennant et al., provides a broad review of academic, economic and societal impacts of open access to research findings. While some consideration is given to economic impacts on non-publishers (which is the main focus of the current review), this is limited to a few paragraphs, and the process by which documents were identified for the review is not described. There is therefore a need for a focused, systematic attempt to identify evidence for economic impacts of open science.

In the next section, I describe the systematized review method, and then go on to present results of the review. I break these down into sections on methods employed to assess economic impacts, the impacts themselves (broken into benefits and costs/challenges), contextual factors, and recommendations made in the reviewed material. I finally draw conclusions and make a number of recommendations.

\section{Materials and Methods}

An REA is a review that uses systematic review methodology to map the characteristics of what is already known about the research topic, and supports decision making by providing evidence on 
topics of policy interest and identify gaps in research (Supplementary Materials). They can be limited in focus to fit with resource constraints and policy timescales, and are now quite widely employed in UK policymaking (e.g., see [11,12]). The main advantages over non-systematic reviews are the level of objectivity they provide as to what should be included, and the increased confidence they give that no important evidence has been missed.

In conducting an REA, there must be a trade-off between the breadth of material which it is possible to cover and the comprehensiveness of the review within given resources. Conducting a systematic and comprehensive review in a narrow area can be preferable because this allows us to say with greater confidence that no key evidence has been missed in the area of focus, and it is subsequently possible to keep this review up to date without having to revisit older material to check for gaps. The scope can be expanded in future as resources become available, again without having to back-track over previously reviewed material.

For this reason, alongside others described in the previous section others described above, this focused predominantly on the economic impacts of free dissemination of research methods and results (open access publishing) and of research data (open research data). Pilot searches suggest that performing a comprehensive review in these subjects will be possible with the resources available, but that adding other relevant subjects (such as open source software for research) substantially expands the amount of material to review. However, where relevant evidence was encountered during the course of a search focused on open access/data (for example, where specific open source software is required to make use of open research data), it will be recorded. For the avoidance of doubt, evidence dealing with open data that is not primarily generated for research purposes is out of scope.

REAs require a protocol to be set out in advance specifying how material will be located, what criteria will be used to assess whether it will be included in the review, what information will be extracted from included sources, and how this will be synthesized. The original protocol for this review is available at https://osf.io/jd3eb. Administrative restrictions meant that it was not possible to share this protocol publicly at the time of the initial review. However, input was sought from a number of leading experts in the open science domain and their recommendations incorporated.

The remainder of this section describes the process that was followed, and highlights any departures from the original protocol, along with a justification. I follow the PRISMA guidelines [13] as closely as possible.

\subsection{Search, Screening and Quality Assessment}

The search strategy specifies how the source material for the review was identified. This was achieved through a combination of online searches, citation checking and expert consultation. Online searches require the concepts of interest to be specified, and then operationalized for use in a search. Table 1 shows the concepts and search terms that have been identified, and shows an illustrative search string for the Scopus database.

The searches are focused on title/abstract/keywords of articles to increase the proportion of hits likely to be directly related to the subject in question, in the knowledge that some relevant results may be missed. Pilot searches indicated that expanding searches to the full text of documents would lead to an unmanageably large number of hits. The search term "open access" has been qualified in the search to minimize the number of results referring to articles that themselves are open access (where the words "open access" often appear in the copyright statement with the abstract). At the protocol review stage, a number of additional search terms were suggested, including abbreviations CBA and BCA, and terms such as "general equilibrium models", "return on investment" and "growth accounting". All searches were recorded and are available to view in Appendix B. 
Table 1. Construction of database search terms.

\begin{tabular}{|c|c|c|}
\hline & Open Science & Economic Impact \\
\hline Concept & $\begin{array}{l}\text { Open science } \\
\text { Open data } \\
\text { Open research data } \\
\text { Open access } \\
\text { Open metrics }\end{array}$ & $\begin{array}{c}\text { Economic impact } \\
\text { Financial impact } \\
\text { Monetary impact } \\
\text { Cost/benefit analysis } \\
\text { Input-output } \\
\text { General equilibrium modelling } \\
\text { Return on investment } \\
\text { Growth accounting }\end{array}$ \\
\hline Search term & $\begin{array}{c}\text { "open scien*” } \\
\text { "open data" } \\
\text { "open research data" } \\
\text { “open access" W/1 publ* OR paper OR journal* OR book* } \\
\text { "open metric*" }\end{array}$ & $\begin{array}{c}\text { econom* } \\
\text { financ* } \\
\text { cost* }^{*} \\
\text { mone* } \\
\text { cba } \\
\text { bca } \\
\text { "input-output" } \\
\text { "general equilibrium" } \\
\text { "return on investment" } \\
\text { "growth accounting" }\end{array}$ \\
\hline $\begin{array}{l}\text { Scopus } \\
\text { example }\end{array}$ & 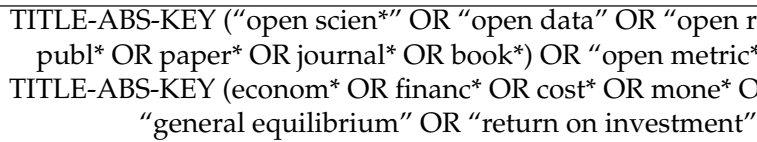 & $\begin{array}{l}\text { arch data" OR ("open access" W/1 } \\
\text { OR TITLE ("open access") AND } \\
\text { ba OR bca OR "input-output" OR } \\
\text { "growth accounting") }\end{array}$ \\
\hline
\end{tabular}

This search strategy was deployed on the following databases which permit Boolean searching:

- Scopus

- Web of Science (all databases)

- $\quad$ ScienceDirect

The following sources were also searched based on combinations of the above search terms.

- JISC

- UK Government website (gov.uk)

- Innovate UK

- UK Research Council and HEFCE websites

- Google scholar (searches of title only, limited to review of first 300 results [14])

- Open Data Institute

- Digital Curation Centre (DCC)

- Nesta

- Centre for Open Science

- Open Research Funders Group

- Open Scholarship Initiative

- Open Access Bibliography

- Open Access Directory

- Universities UK

- OECD Library

- Europa.eu

- European Universities Association

All hits from database searches were downloaded and imported into reference manager software (Zotero v5.0, George Mason University, Arlington, VA, USA). For searches of other sources, results were downloaded where the title and/or initial screening suggests that the document is likely to meet the inclusion criteria. In some cases, where Google was employed to search for sources, results were restricted to PDF documents. This is because pilot searches revealed that without this restriction, 
an unmanageably large number of general (e.g., news page) results were often returned. Reports of empirical research were almost always found to have PDF version available. While this approach risks missing sources, it was considered justified given that other forms of source identification (such as citation checking and expert elicitation) were also being employed, and given the significant time savings it allowed. All documents so far identified as part of the work of the Open Science team were also be captured through a review of internal documents. Two informal discussions were also conducted with experts in the field, and any sources they recommend were captured ${ }^{1}$. As the original searches were conducted in late 2017 with an informal update in early 2018, a limited number of further update searches were conducted during the final preparation of this paper in April 2019.

All references were imported into the systematic review management software EPPI-Reviewer 4 and de-duplicated. They were then screened by a single reviewer on the basis of the inclusion/exclusion criteria set out in Table 2. A first-pass screening done on title/abstract, with a second screening on the full document.

Table 2. Inclusion and exclusion criteria.

\begin{tabular}{ll}
\hline \multicolumn{1}{c}{ Include if Source } & \multicolumn{1}{c}{ Exclude if Source } \\
\hline \multicolumn{1}{c}{ Is in English } & \multicolumn{1}{c}{ Is not in English } \\
\hline $\begin{array}{l}\text { Includes discussion or analysis of making research } \\
\text { methods/findings freely available (open access publishing). } \\
\begin{array}{l}\text { AND/OR Includes discussion or analysis of making research } \\
\text { data freely available (open research data). }\end{array}\end{array}$ & $\begin{array}{l}\text { Does not include discussion or analysis of the economic } \\
\text { impacts of making research methods, findings or data } \\
\text { openly available. }\end{array}$ \\
\hline $\begin{array}{l}\text { Includes explicit consideration (informed by empirical } \\
\text { evidence) of direct or indirect economic impacts (with or } \\
\text { without quantitative value estimates). }\end{array}$ & $\begin{array}{l}\text { Does not explicitly consider economic impacts based on } \\
\text { empirical evidence. }\end{array}$ \\
\hline & $\begin{array}{l}\text { Only considers open source software without discussion } \\
\text { of open data or open access publishing. }\end{array}$ \\
\hline $\begin{array}{l}\text { Reports work in an open access publication or based on } \\
\text { open data, but is not explicitly about these concepts. }\end{array}$ \\
\hline $\begin{array}{l}\text { Focuses only on impacts within the scholarly } \\
\text { communications ecosystem of publishers, universities } \\
\text { and research funders }\end{array}$ \\
\hline
\end{tabular}

The reference lists of all documents still included at this point were checked, and any relevant documents referred to were also loaded into EPPI-Reviewer and passed through the screening process. The final list of included documents was reviewed by a number of colleagues, who were invited to suggest documents which may have been missed-these were screened for inclusion. Any documents which came to my attention at any point were also loaded in and screened. A flow chart showing this process, and the numbers of records retained/removed at each stage, is included in Section 3.

Quality assessment was conducted to ensure that poor quality studies are not given undue weighting when synthesizing evidence. Because of the exploratory nature of this review, no sources were completely excluded on the basis of quality. The TAPUPAS framework was employed to aid assessment of quality, with sources graded on each point from poor ( 0 point) to good ( 2 points) (original protocol stipulated a 1-5 points scale, but this was subsequently considered unrealistically precise). It was also anticipated that for any full economic impact assessments located, the EPPI-Centre data extraction form (economic) Section 7 items would be used for quality assessment. In the event, this more detailed approach was not feasible given project resource constraints.

1 These interviews will also be used to inform and refine the case study objectives and interview schedules.

2 This criterion was added after the protocol was finalised as many documents were identified in this category and, as set out in the introduction, such impacts were not the focus of this review. 


\subsection{Extraction}

Data on the following criteria were extracted from all included sources:

- Organizational affiliation of authors
$\bigcirc \quad$ Academia
$\bigcirc \quad$ Industry
Governmental
O Other non-governmental

- Study country

- Funding source (if applicable)

- Coverage

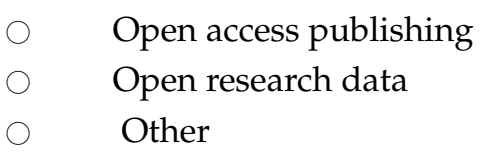

- Key aims

- Data collection and analysis methods

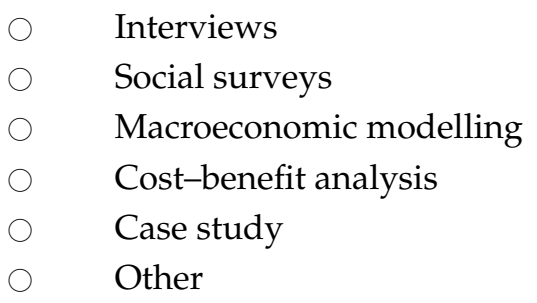

- Key findings (on economic impact)

- Relevant policies cited

- Recommendations

- Quality assessment (scored 0-2)

$\begin{array}{ll}\bigcirc & \text { Transparency } \\ \bigcirc & \text { Accuracy } \\ \bigcirc & \text { Purposivity } \\ \bigcirc & \text { Utility } \\ \bigcirc & \text { Propriety } \\ \bigcirc & \text { Accessibility } \\ \bigcirc & \text { Specificity }\end{array}$

Additional coding of extracted information was conducted in NVivo (qualitative analysis software) to allow identification of key themes.

\subsection{Synthesis}

The results were synthesized under headings aligned with the review objectives presented above. For each objective, a thematic analysis approach was used. For example, to describe the types of economic impact identified in the review, specific examples were collected together under broad common themes (such as 'labour cost savings'). Impact themes were associated with quantitative data where possible (e.g., where examples of financial costs, job growth/destruction, etc., can be allocated under themes). Themes were also be identified in contextual factors, and any consistent associations with economic impacts highlighted (a statistical analysis was not possible). 


\subsection{Updating}

The original review conducted over late 2017 and early 2018. It was therefore updated prior to preparation of this paper in April 2019, by repeating a subset of the original searches, restricted by date to 2018 and 2019 (see Appendix B). Documents identified during this process were screened and data extracted according to the process described above.

\subsection{Description of Results}

The following sections present the results of the review, including a summary appraisal of methods used in the studies which were identified, the benefits and challenges they uncovered (with value estimates where available), a consideration of contextual factors that may be relevant to the results, and a summary of recommendations made in the sources to support benefits maximization. In presenting this kind of synthesis, it is important to bear in mind that the detailed sources that were drawn on often include caveats and contextualization which it is neither possible nor desirable to capture in full. I attempt to detail the main limitations or contextual points where relevant. Please note that these sections also refer to additional literature, beyond that identified in the review, where it can help add useful context or additional information.

\section{General Review Summary}

Figure 1 shows a flowchart of the REA, including number of documents included/excluded at each stage.

The original review identified 20 documents for detailed extraction, with updating providing one additional document, leading to a total of 21. There was substantial variety in the type of study identified, which can present challenges for quality assessment. A quite flexible QA method $\left(\right.$ TAPUPAS $^{3}$ ) was selected in anticipation of this, and ultimately two studies were de-prioritized on the basis of insufficient methodological detail, or justification of findings/conclusions. A further five documents did not present new empirical evidence but were still included because of their relevance to the review questions (for example, one study presented a possible research method).

Five sources described studies focusing specifically on the UK, while the remainder focused on the USA, Canada, Denmark, Finland, or more than one country. All but seven of the sources were published in or after 2014. There was a roughly even balance in coverage between open access publishing (eight sources) and research data (nine sources), with six sources also including consideration of other open science topics. As indicated in the previous section, the review identified a lot of work has been done on the economics of open access publishing, but the vast majority of this focuses on the impacts within the university/publisher/funder ecosystem rather than the broader economy, and was therefore not included.

There was a high concentration of included studies around certain researchers or research approaches. John Houghton, for example, was involved as co-author in six, and many of these studies used similar research approaches. Furthermore, because these studies draw on more diverse evidence sources in comparison to some other included documents (often, for example, combining interviews, surveys and desk research to inform economic analysis, rather than presenting only interview evidence), and more explicitly focus on questions of economic value of open science, they are drawn upon comparatively more heavily in this review. A table summarizing the main aims and methods of each included study is included in Appendix A.

3 https://www.scie.org.uk/publications/researchmindedness/findingresources/assessingresearchquality/. 


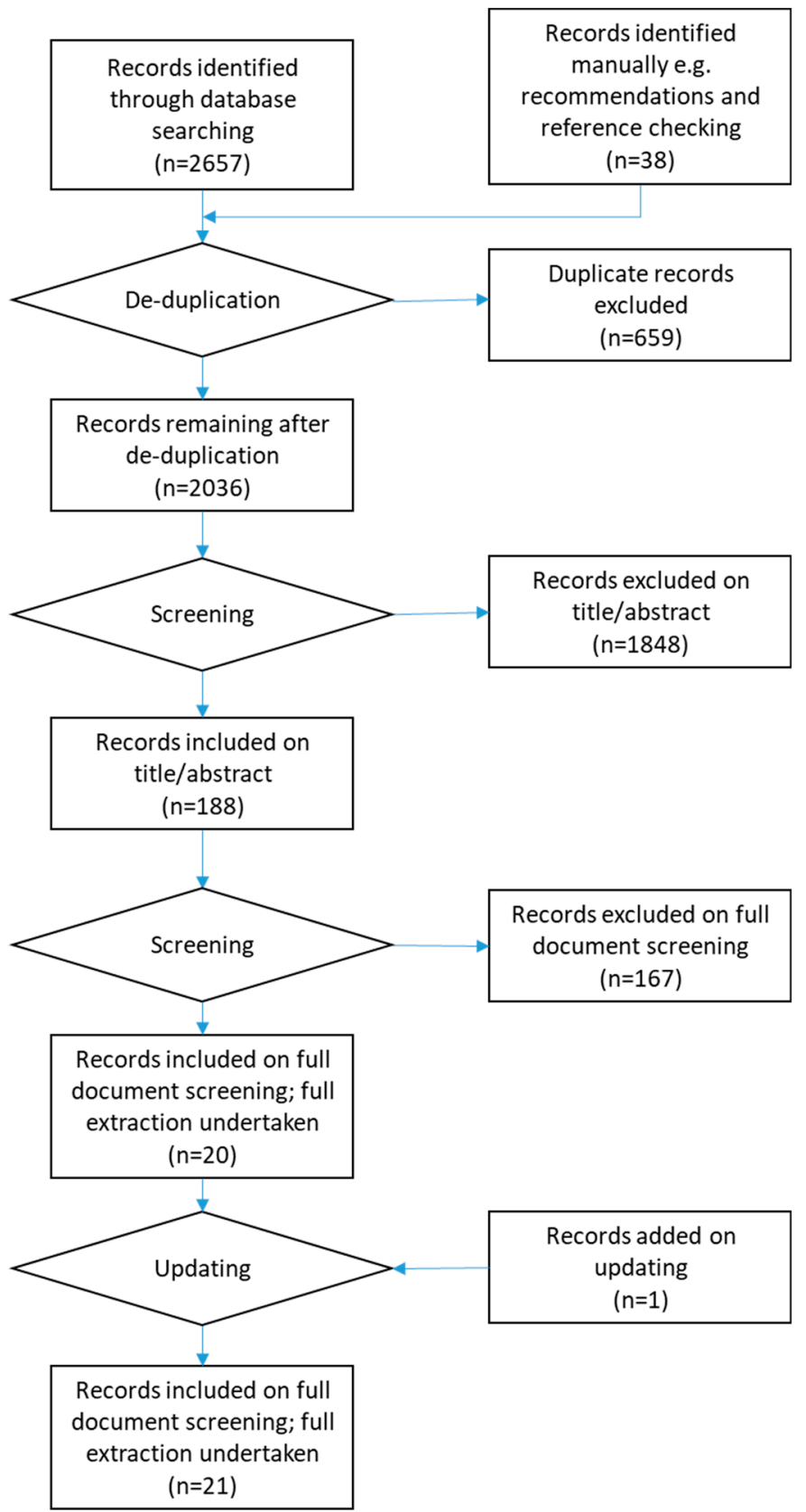

Figure 1. Flow chart showing rapid evidence assessment (REA) process.

\section{Methods for Assessing Economic Impacts}

The review uncovered a diverse range of approaches to gauging the economic impacts of open science. This is likely related, to some degree, to the difficulty in tracking the usage of open science outputs outside of the academic context (where citation practices make this more achievable). Often, users leave no footprint when they access open science outputs, and it there is often no requirement to declare usage. It is possible (although there is no evidence to support this) that firms may perceive it to be beneficial to conceal their use of open findings and data if they believe they derive an advantage from using resources or approaches that competitors may not be aware of. Even if usage is apparent, it is still often difficult to attribute specific economic impacts to the openness of the outputs.

This section sets out the range of ways in which researchers have attempted to combat these challenges and provide value estimates. Principally, these involved using surveys/interviews to elicit user information and opinion, and cost-benefit analysis, sometimes informed by modelling approaches 
(based on desk research on costs/benefits, user input and assumptions). These may be conducted either in the context of a specific case (such as a research collaboration of data repository) or applied more generally (such as at country level). Often, several approaches are combined in the same study. The methodological heterogeneity makes it harder to draw comparisons between findings of separate studies than if standard approaches were employed.

\subsection{Question-Based Approaches}

Where it is difficult to measure revealed behaviour (such as observing actual use of open science outputs), it is common to ask users about their usage instead. In their evaluations of UK data repositories [15] and the European Bioinformatics Institute [16] (along with evaluations in other countries not included here), Beagrie and Houghton used surveys and interviews for this purpose. Interviews were used to help develop the survey content, such as by suggesting which kinds of cost-benefit to include questions about. They also permit more in-depth and detailed insight into how costs or benefits might come about. Interviews are usually only possible with relatively small, non-random samples of participants, and are therefore not suitable for making generalizations to wider populations on, for example, proportions of users affected by certain issues. Interviews were employed in a number of other studies in the review [17-21].

The Beagrie and Houghton surveys asked users to make estimates of factors such as the time spent preparing data for upload, time spent working with data they had downloaded, and the extent to which they would be able to perform their work without access to the open data. Answers to such questions, combined with estimate of salary costs, permit insight into investment in preparing/using open data (known as Investment Value). Among other questions, the surveys also asked users to estimate how much they would be willing to pay to access the (currently free) services, or be paid to forfeit access (willingness to accept). These Contingent Valuation approaches permit estimation of the value placed on free services-with willingness to accept potentially giving insight into value to users whose budgets would prevent them suggesting a high willingness to pay. Subtracting willingness to pay from use value (in a welfare approach) gives insight into consumer surplus. The main drawback with surveys is that it is hard to know how far responses reflect 'objective reality'. For example, in the Beagrie and Houghton work discussed above, respondents were asked to assess how far having access to data in a repository affected their work efficiency (on a percentage scale). Even when pilot testing has been done, it is unlikely that all respondents would interpret such a question in the same way, or be able to come up with an accurate estimate (or even to know exactly what efficiency would mean in this context). The authors are keen to highlight such limitations, but it is easy for such caveats to get lost when key findings are extracted from their context. Surveys were also employed by other studies in the review $[18,21]$.

\subsection{Cost-Benefit Analysis (and Similar) Approaches}

In the studies reviewed, data from surveys and interviews was often combined with information and assumptions based on desk research to inform variants of cost-benefit analysis (CBA). In a standard CBA, researchers sum up the identifiable existing or expected costs and benefits (converted to monetary terms) to which stakeholders in the system of interest are exposed to calculate the overall costs and benefits which accrue, and to whom. For example, in an evaluation of the Human Genome Project, Battelle were able to calculate the value of additional employment provided by the collaboration and organizations connected with it, including the tax revenue this yielded [22]. Assessments of the value of open access publishing such as those by Houghton et al. [23] and CEPA LLP and Mark Ware Consulting Ltd. [24] use best estimates of costs in the existing system and then use modelling approaches to suggest how these might change under alternative publishing models. In their study of the value of text mining (including consideration of the benefits of open access to this), McDonald and Kelly [17] drew on CBA techniques recommended in HM Treasury's Green and Magenta Books (on appraisal and evaluation in central government), and Orange Book (on the management of risk). 
This CBA-like approach such as that used in CEPA LLP and Mark Ware Consulting Ltd. [24] sheds useful light on costs/benefits within the scholarly communication ecosystem, but not the wider impacts on the economy. Multiple works by Houghton and others (for example, see [23]) therefore include an additional modelling step. They employ a modified Solow-Swan model, which is a way of estimating the contribution of technological progress (driven by R\&D) to economic growth. It can be used to estimate a return on investment in $R \& D$ through value to the economy in the coming years. In the sources reviewed, the model is modified to include consideration of the accessibility of R\&D outputs (i.e., the extent to which they are available to inform technological progress) and efficiency with which R\&D expenditure is converted into technological development (which could be potentially be improved by open science practices which help reduce redundancy or improve replicability-see next sub-section). The modified model does not tell us anything about the real extent to which open science approaches could improve accessibility of efficiency (these are based on assumptions), but does provide an indication into what different levels of accessibility/efficiency improvement might mean for value in years to come.

While studies of open access publishing tend to focus on estimating costs/benefits across the sector, much of the empirical evidence on economic impacts of open science more broadly is collected in the context of case studies. For example, this includes studies of research collaborations such as the European Bioinformatics Institute [16], the Structural Genomics Consortium [25], the Research Collaboratory for Structural Bioinformatics Protein Data Bank [26] or of data repositories such as the Economic and Social Data Service [27]. As well as making estimates of the general value of these initiatives using the techniques described above, such evaluations frequently include sub-case studies. In the case of the EBI, for example, part of the work involved conducting impact case studies on specific companies which have been involved in the initiative. By pulling out findings from the research for specific named companies, the research reveals concrete examples of how impact comes about. While the generalizability of such examples is limited, they do serve to illustrate when specific routes to impact are working, or to highlight routes which may otherwise not have been anticipated.

Other approaches employed in evaluation of impacts of open data in general have looked even more broadly at its possible impacts, including consideration of Social Return on Investment (proposed approach only) [28] and wide ranging economic analysis (by McKinsey) of value to sectors such as education, healthcare and oil/gas [29]. This analysis looks at issues such as, in the transportation sector, improved infrastructure planning and management, optimized fleet investment and better-informed consumer decision-making. Specific details of the McKinsey calculations are not provided, but they result in very high value estimates ( $\$ 3$ trillion per year to the global economy). Nevertheless, another open data report for the G20 considers that the McKinsey estimates could even prove to be underestimates [30]. It is important to note that open data in general tends to differ from open research data in ways that are relevant to economic impacts-see subsection on contextual considerations, below.

\section{Economic Impacts}

The review identified a variety of ways in which economic costs and benefits associated with open access to research findings and data, and a number of value estimates. These are set out in the following section. The benefits part is separated into two broad routes-efficiency and enablement.

- Efficiency means getting the same output from research or innovation for less input (principally public research funding). For example, if open access publishing can be shown to allow access to research findings for the same number of researchers for a lower overall cost, this would represent an efficiency saving. While this review is not principally concerned with economic impacts within the university/publishing sector, such efficiencies are also relevant to wider economic impacts through improved returns to R\&D.

- Enablement signifies ways in which open science approaches have led to economically impactful activities which would have been less likely to occur in a closed environment. 
The remainder of this section presents evidence on efficiency and enablement benefits, costs and challenges, contextual issues and the recommendations made by the authors of the documents reviewed.

\subsection{Efficiency}

The main identified efficiency benefits come about in the form of access costs savings, potential for labour cost savings (or productivity improvements), and other benefits such as reduced transaction costs. This sub-section explores evidence for these benefits in more detail.

\subsubsection{Access Cost Savings}

Under a closed model, if a user wants to have access to certain findings or data, they must either pay for that access, or pay to create the findings/data themselves. There is suggestive evidence of savings potential associated with both open to research findings and data. Such savings would accrue both to public funders of research (as researchers are large consumers of research outputs) and commercial users.

Research for Jisc in 2011 [31] found that more than two-thirds (68\%) of researchers in UK universities and colleges felt they did not have access to a sufficiently wide range of journals and conference papers; only $18 \%$ of researchers in industry/commerce felt themselves to have similarly limited access. However, for those participants who viewed having access to journal papers as important, a quarter of those in industry/commerce described their current level of access as fairly/very difficult, compared to just $5 \%$ in universities and colleges. The main barrier to access was unwillingness to pay. Research on access to research outputs in Denmark [18] found examples of companies resorting to workarounds such as establishing formal/informal relationship with university researchers and students to gain access vicariously, or physically going to university library buildings to use their terminals for access.

Houghton and others [23] summed the costs and savings associated with accessing research findings (e.g., production, publishing, dissemination) under open or paid access models. According to their analysis, open access approaches would have been $£ 813-1180$ per journal article cheaper than toll access, equating to $£ 80-116 \mathrm{~m}$ per year (in 2007) for the UK higher education sector, and with similar potential levels of saving relating to book publishing. These figures are disputed, however-especially by those analysts who question the accuracy of the publishing cost estimates [32,33]. This and other analysis [24] have informed the UK's current policy position which is to move towards open access publishing models. Recent research for Universities UK suggests that the costs of transitioning to open access are being impacted by increases in Article Processing Charges [34], which might be expected to negatively impact the net benefits.

Research data, unlike publications, has not tended to be accessed by organizations on a subscriptions basis, so a similar analysis is not really useful in this area. However, recent years have seen a move towards the development of data repositories, where datasets can be accessed for free by most users with no or minimal registration requirements. Beagrie and Houghton conducted studies in an attempt to evaluate the savings that arise to users through having access to such repositories. These include the Economic and Social Data Service (ESDS, now integrated into the UK Data Service) [27], the Archaeology Data Service (ADS) [35], the British Atmospheric Data Service (BADS, now part of the CEDA Archive) [36] and the data repositories curated by the European Bioinformatics Institute (EBI) [16]. It is important to note that some of these repositories do not only include open research data, but also a substantial quantity of open government data. The values included below do not distinguish between the different sources of data, so will overestimate the value connected with (solely) research data. Access to most UK Data Service data is only free for research and teaching purposes; commercial users are required to pay.

The authors used surveys to ask users (mostly from the research sector) of these services what they would pay to retain access (willingness to pay), and what payment they would accept for loss of access (willingness to accept). They also asked users to estimate how much time they spent using the service 
(and preparing data to submit to it), to which it was possible to apply a labour cost. As highlighted in the section of this paper considering methods, getting an accurate estimate of willingness to pay/accept from surveys can be difficult for reasons including respondents' own difficulties in estimating value, incentives to obscure true value estimates, and mismatch between valuations and real purchasing behaviour [37].

These caveats accepted, in the case of the ESDS they found a consumer surplus of $£ 21 \mathrm{~m}$ per year-that is, users expressed willingness to pay $£ 21 \mathrm{~m}$ more than the $£ 4 \mathrm{~m}$ they were currently investing in labour costs to use the service. Given the cost of running the service of roughly $£ 3 m$ per year, this equates to a net economic value of $£ 18 \mathrm{~m}$ per year, or more than five times the cost of running the service. A similar study on the European Bioinformatics Institute suggests that users' willingness to pay, at around $£ 322 \mathrm{~m}$, exceeded the annual operational budget of around $£ 47 \mathrm{~m}$ by approximately six times. A study which employed similar methods to estimate the economic impact of the Research Collaboratory for Structural Bioinformatics Protein Data Bank also found large positive returns-for example, contingent value (or hypothetical willingness to pay multiplied by number of users estimated on the basis of website visits) was more than 100 times greater than the project's annual operating cost [26]. It should, however, be noted that this study relies extensively on assumptions based on previous valuation work.

Measuring users' willingness to pay can underestimate the value they attach to a service where those users are quite resource constrained. This was the case for the ADS, where users' willingness to pay for the service was sufficiently low that the consumer surplus and net economic value were negative. The authors argue that in some cases (for example, in sectors where funding is relatively scarce) it is more instructive to focus on users' willingness to accept payment for lack of access, which has no resource constraints. If this is used instead of willingness to pay, a net economic value for the service of roughly eight times the $£ 700 \mathrm{k}$ operational budget is achieved. The authors note a similar resource constraint for users of the BADC, although in this case their stated willingness to pay still suggests a positive net economic value of just under $£ 1 \mathrm{~m}$, on an operational budget of just over $£ 2 \mathrm{~m}$. These specific examples illustrate the challenges in providing anything more than very general indications of the potential economic impact of free resources, and provide (at best) limited evidence for benefits potential.

As well as reducing direct costs associated with access to research outputs, open science approaches can help reduce transactions costs. The Structural Genomics Consortium is a collaborative research body that aims to support drug discovery by sharing open access information on pre-competitive biological structures ${ }^{4}$. An evaluation of its work found that its open collaborative approach avoided the direct and labour costs of establishing multiple material transfer agreement between partners [25]. Another study has estimated that the costs of such agreements for a single collaboration can run into the hundreds of thousands of dollars [38], so given the extensive collaboration (between hundreds of facilities) that the SGC has enabled, this element of saving is likely to be considerable.

Transaction cost savings are also likely to arise for text/data mining uses. Under normal circumstances, those intending to text/data mine are required to reach agreement for such usage with multiple publishers and content providers [17]. The introduction of a text and data mining copyright exception has reduced this burden for non-commercial uses, but commercial use is still restricted and there are other barriers related to mass downloading of material and sharing of outputs [39]. Campaigns are underway at the EU level to address such issues [40]. As well as the costs and time required to reach such agreements, it also introduces significant uncertainty into such projects as it is possible that some agreements may not be reached. Open access approaches have the potential to mitigate such $\operatorname{costs}^{5}$.

4 https://www.thesgc.org/about/what_is_the_sgc.

5 Please note, however, that no financial estimates were discovered for the scale of such savings. 


\subsubsection{Labour Cost Savings or Productivity Improvements}

It takes time for firms and researchers to actually access research outputs, and this time is reflected in labour costs. It can take longer for people to access closed research outputs than when access is open. A survey in Denmark by Houghton, Swan and Brown found that knowledge-based SME employees spent on average $51 \mathrm{~min}$ to access the last research article they had difficulty accessing, and this rose to $63 \mathrm{~min}$ for university researchers [18]. Given they reported difficulty accessing 17 articles per year, the cost of such delays based on average staff salaries could amount to $€ 70 \mathrm{~m}$ (although the authors note that their sample was not representative $)^{6}$. This is a cost that could, in theory, be saved if all access barriers were removed. However, the actual time saving associated with open access was not tested. Support was also found for this potential saving in an interview-based study by Parsons et al. [19].

The data repository evaluations by Beagrie and Houghton referred to above also attempted to estimate the time savings that accrued to users of the repositories. This was done by asking them to estimate how many hours they spent working with repository data (to which a value could be attached based on average salaries), and to use a percentage scale to estimate how much more efficiently this allowed them to use their time than if the repository were not available. This is clearly a difficult assessment to make, and the researchers report problems associated with participants interpreting the questions in different ways. However, open-ended response fields allowed some insight into this interpretation-for example, users taking into account reduction in form-filling, traveling to on-site/supervised repositories, and efficiencies associated with the format of the data. Using these responses, the researchers suggest that there may be efficiency gains worth $£ 68-100+m$ per year for the ESDS, and smaller but also positive savings for ADS $(£ 13-58 \mathrm{~m})$ and BADC $(£ 10-58 \mathrm{~m})^{7}$. They estimate the equivalent savings for the EBI at approximately $£ 1-5$ billion, at least 20 times more than the direct operational cost.

As well as making individual research outputs easier to access, open access can also facilitate text and data mining, which allows generation of new information through analysis of large bodies of text or data. One of the key benefits of this is that time taken to extract useful information from sources can be reduced (compared to manual approaches). It is difficult to estimate what the level of time saving might be, but McDonald and Kelly suggest the following [17]:

If text mining enabled just a $2 \%$ increase in productivity corresponding to only 45 min per academic per working week, this would imply over 4.7 million working hours and additional productivity worth between $£ 123.5 \mathrm{~m}$ and $£ 156.8 \mathrm{~m}$ in working time per year.

It should be noted that some applications of text and data mining, such as filtering and presenting only relevant research to users, risk negative consequences such as missing key evidence unless a substantial proportion of available content is available for mining.

\subsubsection{Other Efficiency Benefits}

There are a number of other ways in which open science could lead to more efficient research, and therefore more positive economic impact. It is estimated that closed research can lead to high levels of duplication-that is, where separate teams work on the same thing unbeknownst to each other. While the closed nature of the research inherently makes the extent of this hard to estimate, an analysis of pharmaceutical patents by 18 large companies showed that $86 \%$ of target compounds were investigated by two or more companies [41]. It is important to draw a distinction between duplication and replication (the latter of which can help increase confidence in conclusions); duplication is a problem because multiple companies may invest in developing a compound (or other innovation) that has already been demonstrated to be ineffective [42]. Redundancy in research goes wider than

\footnotetext{
For comparison, UK GDP is approximately 8.5 times that of Denmark.

Please note that the authors emphasize that, because of some differences in the way these figures were calculated between studies, they are not directly comparable with each other.
} 
questions of open science and is connected with challenges such as general under-publication of 'null' results [43]. However, open approaches such as pre-registration of trials could help ameliorate the situation, in this case by helping to reduce suppression of 'null' results and therefore potential for wasteful duplication of approaches which have been shown to be ineffective. Text and data mining could also make it easier to identify previous findings [17]. The challenge of decreasing research productivity has been highlighted [44]; the above factors have the potential to mitigate this.

So far, the evidence has focused on efficiency, or doing the same with less input. The implication here, for example, is that firms are able to access research findings and data in closed situations, but just at higher financial and other resource costs. However, there are also mechanisms by which an open approach can enable access, connections and collaborations that would not have happened, or would have happened more slowly, otherwise. This is the subject of the next section.

\subsection{Enablement}

Enablement benefits come in the form of new products, services, companies and collaborations, as well as permitting work that could not otherwise have been undertaken.

\subsubsection{New Products/Services/Companies}

It has been suggested that open science approaches have the potential to lead to the development of new products, services, companies and even industries $[30,45]$. This review did not reveal any economy- or even industry-wide attempts to estimate the extent to which this has taken place. However, it did identify a number of case studies that demonstrate the existence of such mechanisms and provide some insight into the circumstances under which they come about. These examples are all drawn from the life sciences (see section on contextual issues below for further discussion of this).

Probably the largest project to make research data openly available was that Human Genome Project, which ran from 1990 to 2003 and was funded principally by the US government (at $\$ 3.8$ billion). Data were made publicly available within $24 \mathrm{~h}$ of discovery [46]. The availability of the human genome has led to the development of new diagnostic tests and technologies, and informed many new disease treatments and treatment approaches [46]. For example, use of genetic information has informed new tests which allow anticipation of the likelihood of adverse reactions-this reduces harm to vulnerable patients, while allowing effective drugs to continue to be used in people to whom they do not pose a risk [22]. Further products and services have been enabled in a range of domains, from agriculture and environment to forensics and industrial biotechnology. An economic impact assessment of the project found that it generated 'an economic (output) impact of $\$ 796$ billion, personal income exceeding $\$ 244$ billion, and 3.8 million job-years of employment' (pES-2) [22].

Because that report does not focus on the 'openness' of the project in particular, it does not permit assessment of how the benefits would have compared under a more closed model. However, other research has taken advantage of the fact that a parallel, comparatively closed sequencing effort (run by the firm Celera) yielded data with some IP protection [47]. It estimates that 'Celera's IP led to reductions in subsequent scientific research and product development on the order of 20-30 percent' (p. 24), a result of the additional transaction costs that using Celera data would impose. This finding is caveated that this may not represent research effort that was 'lost' - it may simply have been focused on non-Celera genes.

There are examples of new products and companies emerging from other, similar projects. The Structural Genomics Consortium is a not-for-profit public private partnership which conducts research on protein structures, releasing structural data freely and without patent protection [48]. An evaluation found that about half of a small sample of researchers surveyed (17 respondents) believed that their research would lead to development or trialling of a pharmaceutical product in future, and three people reported that their research already had this outcome [25]. A good example is JQ1, a compound that research through the Consortium suggested may be used to inform development of cancer treatments. Following this discovery, GlaxoSmithKline started its own proprietary research 
programme which led to a clinical trial within two years [49]. Research that later compared the number of patents connected to the JQ1 discovery found that after four years, 105 patents had been filed, compared to a mean of 29 for two similar compounds which were not released openly [50]. Three spin-out companies have resulted from the work of the SGC, with one, Tensha Therapeutics, connected with JQ1 [49]. It received \$15m initial investment, and was acquired within a year (by Roche) for $\$ 535 \mathrm{~m}[51]$.

\subsubsection{Collaborations}

As before, it is not always clear that new products or companies would not have appeared had the originating project not been open in nature. However, the experience of the SGC points to an additional benefit that such open models can yield that means that research can happen that may not have done otherwise - that of new pre-competitive multi-stakeholder collaborative research. A case study of the consortium [52] highlighted the potential conflicts that can arise in standard university-firm partnerships, such as firms' desire to appropriate knowledge outputs running counter to academics' requirement to publish openly, or for universities to make their own IP claims. The SGC managed this in a variety of ways, such as by revealing lists of target proteins without attaching companies' identities to them (so protecting companies' research interests), and not revealing the list of targets publicly. Instead, protein structures were released only when resolved. By providing such assurance-identified as 'meditated revealing' and 'enabling multiple goals' - the SGC was able to attract funding from the Wellcome Trust, GlaxoSmithKline, Novartis, Merck, government organizations and other smaller foundations. In 2011, the consortium reported the addition of two new members, including Pfizer, and that together the consortium members were committing $\$ 50 \mathrm{~m}$ for the next four years of research along with $\$ 9 \mathrm{~m}$ in-kind contributions [53]. Another major open collaboration is in its early stages at the Montreal Neurological Institute and Hospital [54]. While no evaluation is yet available of its impacts, an evaluation plan is in place which will also look more broadly at impacts of open science approaches internationally, potential for new metrics, and other relevant questions [55].

Open science collaborations are also appearing in other subject areas, such as the SPOMAN (Smart Polymers and Nano-composites) project at Aarhus University [56]. In this case, the focus is more on collaborative ideation, with partner companies being involved in determining research priorities. The research is focused on fundamental knowledge and partners may not patent it. Instead, all outputs (included data, code and lab notebooks) are shared openly, with companies being free to file patents on specific applications of the findings. No economic evaluation is yet available on the project.

\subsubsection{Permitting Work}

A key enabling contribution of open science outputs can be to permit further research that would not otherwise have been possible. For example, the evaluation of the European Bioinformatics Institute found that $45 \%$ of survey respondents could not have either found the data they access through the repository themselves, not created it themselves [16]. Work based on this data can therefore be viewed as additional to what would have occurred had the Institute not existed (although any such counterfactual must take into consideration how funding for the Institute might otherwise have been deployed). A similar proportion of survey respondents to the Economic and Social Data Service evaluation reported this also (330 out of $894,37 \%$ ) [27].

It has also been suggested that enhanced text- and data-mining capabilities permitted by open approaches (as outlined above) can result in previously hidden connections between different areas of research being unveiled [17]. The example is provided of a tool which was used to analyse disjoint biomedical literatures to identify possible new disease targets for the drug thalidomide, which could then be subject to further research which might not otherwise have occurred [57]. As highlighted above, if $R \& D$ is expected to have positive growth impacts in the economy, then any research which is permitted by open science outputs and which is genuinely additional (for example, as compared to duplicating existing data) contributes to this. 
As discussed in the 'methods' section above, macroeconomic modelling approaches have been used to explore the potential impact of more open science approaches on the returns to R\&D in the wider economy. Specifically, they look at the impact of varying the following factors [58]:

- Accessibility, or the extent to which research findings can be accessed by users.

- Efficiency, or the extent to which R\&D generates knowledge that is useful socially or economically.

The variables summarize many of the impacts described above. Such modelling requires many large assumptions, so the results are naturally highly caveated. However, it has been estimated that a conservative $5 \%$ increase in accessibility and efficiency in the UK could have been worth $£ 172 \mathrm{~m}$ per year in increases returns to public sector R\&D [23]. Because such returns are experienced year after year (assuming the accessibility/efficiency gains are permanent), this can contribute to increased growth.

\subsection{Costs and Challenges}

The review also set out to see if there was evidence of open sciences approaches having negative economic impacts. While many examples of specific additional or different costs were identified (such as extra costs of preparing datasets for publication or payment of Article Processing Charges), none of the overall value estimates located were negative. Going beyond direct costs, a number of ways were proposed in which either the full benefits of open science might not be realised, or there may even be some negative effects. However, none of the work identified attempted to put a value on these effects. This section summarises the evidence underpinning these concerns.

There were a few suggestions that a lack of capacity within firms (and elsewhere) to make use of outputs from open research diminished their potential to have benefits. For example, work by Houghton, Swan and Brown, in Denmark found that the second most cited difficulty in accessing findings was simply searching for an article online, but not being able to find it [18]. The authors suggest that this points to a lack of higher-level information literacy skills amongst SMEs. Johnson et al. [59] point to the potential for similar skills shortages to lead to lack of the accountability that open data (in general) is purported to bring, and similarly the lack of awareness of the value of text mining is highlighted as a reason for the lack of full benefits realisation via that route [17]. Huber et al. [60] also highlight awareness and skills barriers to maximizing benefits from open data (not just research data) — but also highlight further barriers including uncertainty around future availability of data, the risk of imitation (as others also have access to the data), and legal and reputational risks.

Important questions are also raised about where the benefits of participating in open science accrue, and what this might mean for the conduct of research in general. Part of this is directly related to the rewards of commercialization. For example, while early stage research collaborations such as the SGC have proved successful, later stage applied research (with more immediate expectation of benefits) has been less amenable to open approaches due to firms' perceived difficulties in protecting intellectual property at this stage [42]. Morgan argues that if governments can provide 'regulatory exclusivity' to drugs developed in an open way, this could provide an alternative form of protection [61]. There is also the question of indirect benefits or disadvantages to researchers of conducting open research. The potential conflict is highlighted of institutional expectations to publish in certain journals, which may not provide open access [62]. Researchers may also be concerned about lack of credit for producing open science outputs [63].

Some work has focused on the potential incentive for researchers to delay publication of papers because such publication would come with a requirement to share their data, potentially diminishing their opportunity fully exploit it [64]. The requirement to share data could even act as a disincentive to collect it (because the researcher may expect to be able to reap the full benefits of their data collection work). The research, a modelling study which examined researcher incentives to generate and share data, found that if mandatory data disclosure requirements led to strategic delays in publication, this could affect the overall (economic) welfare of the research community. 
There has been additional speculation that researchers may perceive a tension between their institutions' or funders' expectations to commercialize their work, and the desire or requirement to share findings and data openly. While in principle such a tension can be shown to exist (in the policy statements of individual funders regarding commercialization and openness), there is as yet no empirical evidence that researchers recognize it [65]. This review did not reveal any cost-benefit analyses of the value to the economy of direct commercialization of publicly funded research (e.g., by university patents or spinouts) compared to commercial exploitation of open science outputs. Finally, in the context of open data in general, the issue was raised of whether public funding for data which is likely to be of commercial use represents a subsidy [59]. This could be a concern if the commercial offerings informed by the data had limited benefits for citizens.

\subsection{Contextual Issues}

The review revealed concentrations of open science approaches in some research areas. All the economic evaluations of public/private open research collaborations focused on the life sciences-such as the HGP, SGC and EBI. The common factor was a desire amongst collaborators to jointly support (rather than duplicate) basic analysis which could subsequently be used to inform product development. As Savage points out, efforts to extend such collaboration further into the drug discovery process have met with less success [42]. Economic evaluations were not found for collaborations adopting open approaches in other areas. The reasons for this are not clear-it may be that decreasing rates of translation of basic discoveries into commercial treatments, combined with the expiry of existing drug patents, has led pharmaceutical companies in particular to embrace open innovation approaches [66]. The sector is also subject to strong regulation which may incentivise cost sharing more than in other sectors. However, there is no reason to think that life sciences is unique in offering the possibility for collaboration on basic research to underpin future developments. There is the example of SPOMAN [56] in materials science (as described briefly above), and a potential parallel in the example of the National Geological Repository (NGR), operated by the publicly funded British Geological Survey. A Natural Environment Research Council impact study highlighted the role of core samples made openly available by the NGR in increasing the efficiency of drilling and geotechnical companies' operations.

There is some evidence to suggest that economic impacts may be more likely to accrue to certain types of commercial actor. A survey by Ware [67] found that $86 \%$ of large firm respondents reported accessing research information through company subscriptions compared to $77 \%$ of small and medium sized enterprises (SMEs), while use of open access sources was $68 \%$ in large firms compared to $71 \%$ in SMEs. On a monthly basis, $27 \%$ of large firms' respondents used an in-house information service compared to $15 \%$ of SMEs. While Ware does not explicitly make this point, it therefore seems likely that SMEs would stand to gain disproportionately from an increase in open access to research findings, although this does not take into account factors such as capacity to make use of such information (see recommendations section below).

Based on wider (informal) reading of the literature on open data business models, it is apparent that many rely on access to real-time data such as on meteorological or transport conditions (e.g., CityMapper ${ }^{8}$ ). While there are examples of real-time open research data feeds (such as LondonAir ${ }^{9}$, which provides information on levels of air pollution), the examples identified in the review were exclusively concerned with discrete, fixed research datasets. Even in cases where data is released on a frequent basis (such as in the Human Genome Project, which released data within $24 \mathrm{~h}$ of collection), this does not permit CityMapper-like business models, meaning this avenue for commercialization is likely closed off for the majority of open research data. The case has also been made that the granularity of research data reduces its commercial potential. Tim Vines, writing on the Scholarly Kitchen website,

8 https://citymapper.com/london.

9 https://www.londonair.org.uk/LondonAir/Default.aspx. 
argues that unlike social media or city data which have individuals or locations as a common thread, most scientific datasets are 'small and collected to answer a very specific question' [68].

In some of the sources reviewed, there is discussion of localisation (to the country of origin) of returns to R\&D and, by inference, open access to research findings/data. For example, Houghton and others [23] draw on previous suggestions that domestic knowledge should be weighted at $66-73 \%$ compared to $27-33 \%$ for foreign knowledge in terms of value to the domestic economy. However, they do not make an estimate for whether/how opening access to findings and data might affect these weightings. At the very local level, no evidence was found regarding economic impacts in the direct locality of research teams producing open outputs. However, as mentioned in the 'Efficiency' section above, firms do sometimes benefit from proximity to a local university by accessing research information in their library. An increase in open accessibility of findings/data may make such proximity 'workarounds' less important.

\subsection{Recommendations Captured in the Review}

Many of the documents included in the review included recommendations related to increasing positive economic impacts of open science and support further study. The majority of the recommendations are based in general promotion of open science approaches. This might include, for example: ensuring that funding is available for data preparation or publishing fees [23]; increasing provision of institutional or subject repositories [23]; creating more data journals [64]; and encouraging universities to support immediate data disclosure [64]. There was also a call for special access conditions to research outputs for text and data mining [17]. There were some recommendations to focus attention on awareness of the benefits of use of open science outputs [20]. Parsons et al. found that lack of search skills and interpretive expertise was highlighted as a barrier to use of open access resources [19]. They recommend making repositories more user-friendly (such as by simplifying user interfaces, providing lay summaries, improving business-relevant metadata and advising academics on how to present findings for business audiences).

Specifically in relation to economic impacts, the most common call was for more research, monitoring and evaluation in this area, aided by identification of new metrics. As previous sections have highlighted, there is a lack of available, comparable data on actual use of open science outputs in a way that would allow identification of economic impacts. Research has tended to rely on either reported use (e.g., through surveys), assumptions, or detailed case studies. Conventional research indicators such as citation counts have little relevance to questions of economic impact, while innovation indicators such as patents are either less relevant (in the context of open innovation) or yield little insight on the contribution of open science outputs to the innovation. Without strong evidence for ways in which positive economic impacts of open science can be maximized, it is difficult to design effective support policies.

Reflecting on their evaluations of data repositories [15] and the EBI [16], the authors recommend that such bodies collect/report more data on costs, usage and users (voluntarily), and that data be collected in standardized ways allowing more comparative and granular analysis. Initiatives are underway that could support this, such as Crossref's DOI Event Tracker pilot [69]. Houghton and Sheehan [45] called in 2006 for development of better ways of tracking the translation of knowledge generated by R\&D into economic value (and how this depends on openness of outputs), and identifying the extent to which value is localized or spills over to other localities. While there has indeed been progress in research on these areas (e.g., $[70,71])$, the review did not identify evidence on economic impacts of open science incorporating these developments (although research is underway at McGill university in Canada that will include consideration of local impacts [55]). Chataway et al. [62] point out the need for a better understanding of how open access to research outputs influences firms' use of research, especially in the case of research data. They highlight efforts that are underway to support this [72]. Houghton et al. make the case for research metrics and incentives that better reflect the value of innovative open models of research communication [23]. Parsons et al. [19] provide a package of 
research recommendations including on how open access status affects search engine discoverability, awareness and use of open materials in different organizational contexts, usability of repositories to business users and the role of different organizational/capacities in enabling use of open materials.

\subsection{Study Limitations}

As with any evidence review, there is a risk that I have missed documents which highlight other positive or negative economic impacts of open science. The study protocol, which involved a broad search strategy combined with citation tracking and expert input/review, was designed to minimize the chances of this-but it is still a possibility. Resource constraints meant that the screening/coding was conducted by me alone; having a second coder would increase confidence that my decisions on what content to include/exclude, and subsequently record, were correct. Again, however, I hope that expert input received throughout the process of developing and conducting this review will have largely mitigated this risk.

More broadly, in the abstract of this article I characterize the evidence in this field as patchy and diverse. I have attempted to highlight the merits and drawbacks of different research approaches. However, we should also bear in mind that there is the risk of systematic bias in the studies that are conducted and/or published. The challenge of publication bias (where authors, editors, reviewers, etc. are less likely to submit or accept 'null' results or those than run contrary to expectations or even desires) is well-known [73]. We should ask whether researchers (or project funders) are as likely to choose to examine/evaluate examples of open science that are not conspicuously successful compared to those that are. They may be, but it is impossible to say for sure-and the techniques employed in quantitative meta-analysis to recognize this (such as funnel plots) are not deployable in the case of this review. We should also consider that there is likely to be a strong social desirability bias around open science - the idea that there should be free and easy access to research findings and data is, taken at face value, always going to be hard to dispute. Research participants might be expected to tend to support this view. To be clear, this is not to suggest that any of the studies here have been conducted in a biased way. Rather, we should remain alert to the possibility of 'missing' findings where research scrutiny has, for various reasons, not been brought to bear-and the chance that these may be more likely to be negative. This is another motivation for the call for more research identified in many of the sources reviewed, and which I repeat myself.

\section{Conclusions and Recommendations}

\subsection{Conclusions}

In this paper, I have presented the results of a Rapid Evidence Assessment which set out to identify the best available evidence of the economic impacts of open science. This section briefly summarizes the key findings and considers their possible implications for policymakers.

Use of open science outputs (e.g., by firms) often leaves no obvious trace, so most evidence of impacts is based on interviews, surveys, inference based on existing costs, and modelling approaches. For example, surveys have been used to ask open data users how much time they spend searching for data and how this is reduced when the data is open, then using salary estimates to assess labour cost savings. Willingness to pay/accept approaches have also been used to estimate the value of free resources. Such approaches introduce significant potential for measurement error, and assumptions on existing costs (such as those involved in publishing findings) are often disputed.

The review identified evidence that open access to findings and data can lead to positive economic impacts through (a) efficiency and (b) enablement, but the evidence base is patchy and diverse. Efficiency means getting the same output from research or innovation for less input (principally public research funding). For example, if open access publishing can be shown to allow access to research findings for the same number of researchers for a lower overall cost, this would represent an efficiency 
saving. Enablement signifies ways in which open science approaches have led to economically impactful activities which would have been less likely to occur in a more closed environment.

Regarding efficiency, there is indicative evidence that open access to findings/data can lead to savings in access costs, labour costs and transaction costs. Open access should lead to cost-savings in the university/publishing ecosystem, although (as highlighted above) modelling assumptions are disputed and there are significant costs in transitioning to some models. Open access could reduce costs to firms of accessing research findings (or increase availability), although this may only be a 'latent' savings if firms do not have capacity to access/use findings/data. Easier access to research findings/data can reduce time required to access them, saving labour costs. There is some evidence of reduction in transaction costs, such as material transfer agreements or for text mining (although open access in itself does not eliminate such barriers except for non-commercial uses, where a text and data mining copyright exception applies).

There are examples of open science enabling new products, services, companies, research and collaborations. Multi-stakeholder collaborations such as the Human Genome Project, Structural Genomics Consortium and European Bioinformatics Institute were enabled by agreements around early, open release of data. The SGC revealed a compound (JQ1) which had cancer treatment potential. GSK has gone to clinical trials with products based on this. Research that later compared the number of patents connected to the JQ1 discovery found that after four years, 105 patents had been filed, compared to a mean of 29 for two similar compounds which were not released openly. Three spin-out companies have resulted from the work of the SGC, with one, Tensha Therapeutics, connected with JQ1. It received $\$ 15 \mathrm{~m}$ initial investment, and was acquired within a year (by Roche) for $\$ 535 \mathrm{~m}$. Evaluation of the European Bioinformatics Institute found that $45 \%$ of survey respondents could not have either found the data they access through the repository elsewhere, nor created it themselves.

Modelling studies indicate higher returns to R\&D with the greater accessibility and efficiency that open access allows. Macroeconomic modelling approaches have been used to explore the potential impact of more open science approaches on the returns to R\&D in the wider economy. Specifically, they look at the impact of varying the following factors:

- Accessibility, or the extent to which research findings can be accessed by users.

- Efficiency, or the extent to which R\&D generates knowledge that is useful socially or economically.

It was estimated in 2009 that a conservative 5\% increase in accessibility and efficiency in the UK could have been worth $£ 172 \mathrm{~m}$ per year in increases returns to public sector R\&D. Such models include many general assumptions.

While the review identified specific additional or different costs associated with greater openness (such as extra costs of preparing datasets for publication), none of the overall net value estimates located were negative. Key barriers to use of open science outputs included lack of skills capacity in search, interpretation and text mining, and lack of clarity around where benefits accrue. There is evidence for lack of higher-level information skills amongst SMEs. Modelling work has suggested that mandatory data sharing could cause researchers to delay publication, affecting overall welfare of research community. There are suggestions (but little evidence) of tension between pressures to commercialise research and a more open approach.

There are also contextual considerations around who benefits most from open science (e.g., sectors, SMEs vs. larger companies, types of dataset (e.g., real-time vs. static), extent of local benefits. All the major research collaborations evaluated were in the life sciences, with collaborators jointly supporting basic science. Later stage research collaborations have met with less success. SMEs are less likely to have institutional subscriptions (e.g., to journals) than larger companies so could benefit more from free access, but they may also be subject to more time and skills constraints. Research data tends to be more static and granular than other forms of open data (e.g., public transport departures), reducing its commercial potential. There is as yet no evidence on the role of open science in localization of benefits, although previous general estimates have suggested that domestic knowledge has more value locally than foreign knowledge. 
Recommendations include more research, monitoring and evaluation (incl. metrics), promoting benefits, capacity building and making outputs more audience-friendly. There is a lack of available, comparable data on actual use of open science outputs-where possible, repositories and open collaborations should collect more data on costs, usage and users. A toolkit for tracking open science impacts has recently been developed to help improve and formalize this process [74]. Research is needed on how openness affects local vs. global return to R\&D. Better understanding is needed of how firms make use of R\&D outputs, including open outputs. Consideration should be given to promoting the benefits of open material and building capacity within firms to locate and use it. Repository design and content could be improved to make access and use easier for a wide range of users (such as by simplifying user interfaces, providing lay summaries, improving business-relevant metadata and advising academics on how to present findings for business audiences).

\subsection{Recommendations}

The above findings demonstrate the potential of open science to provide a range of economic benefits. On the basis of these findings, I make the following recommendations for policymakers and research funders. These intentionally do not include measures to either increase the quantity of open outputs available, or the usability/interoperability/etc. of these outputs-these are goals of broader open science policy. Instead, they focus on specific ways in which the positive economic impacts of open science might be maximized. The relevance of each recommendation will vary depending on country context.

Promote and support new open collaborations. This review provides a number of examples of multi-stakeholder public-private collaboration to tackle pre-competitive research challenges. These were shown to support increases in R\&D funding and development of new products and companies. Research funders should review their areas of responsibility for subjects meeting appropriate characteristics (i.e., basic research likely to inform subsequent innovation, multiple large private competitors, significant regulatory burden) and promote collaborations in areas revealed as suitable. General principles and guidance should be developed to balance a requirement for openness with corporate partners' commercial considerations (as for the Structural Genomics Consortium Open Science Trust Agreement). The benefits of such collaborations should be fully explored and actively promoted to potential commercial partners.

Streamline text and data mining. At the moment, there is an array of licence conditions even around many open access outputs that represent barriers to text and data mining, either forbidding it or putting up excessive transaction costs. In the UK, a text and data mining (TDM) copyright exception has gone some way to addressing this, but still precludes commercial applications and presents other barriers. This is also a live issue at the time of writing as debates continue around the introduction of the new EU Directive on Copyright in the Digital Single Market. Licensing should be further simplified with a presumption that text and data mining are possible in a wider range of applications (campaigns are underway at the EU level to support this). Infrastructure should be put in place to support TDM access to open access material for firms and academic libraries. The EU-funded OpenMinTeD project is a possible example of such infrastructure [75].

Develop an open access findings/data portal targeted at business. Most infrastructure for the outputs of research is primarily targeted at the research community, which may diminish its usability and apparent usefulness to many companies. Dedicated portals should be developed (informed by user research and building on lessons from previous similar initiatives) which provides a more relevant front-end architecture, for example, categorizing open outputs by relevant business sector or business function, and prioritizing lay summary information where available. To minimize resource requirements this could take the form of an overlay on existing repository infrastructure. A curation service could allow datasets or streams which appear most likely to be useful to business (determined by characteristics such as ability to link to other datasets, real-time, etc.) to be foregrounded or even actively pushed to suitable businesses. Such portals would also act as a focal point for promoting 
the business benefits of open science outputs and providing support and training material for those businesses seeking to extract most value from such outputs. Models for this exist in the form of services such as Konfer [76] and the new LORIC centre at Bishop Grosseteste University [77], and universities could have a key role to play as neutral, trusted convenors.

Produce aligned positions and guidance on open science and commercialization. There are potential contradictions in the aims of policies intended to encourage open science and those promoting commercialization of research. While there is currently little evidence on the extent to which institutions and researchers perceive contradictions, to avoid confusion there should be consistency both in the word and intention of policy. Countries should review policies and measures intended to promote commercialization and open science. Based on analysis of areas of complementarity and contradiction and existing empirical evidence on how the two can most effectively be balanced, a position and guidance should be developed which address the priorities and concerns of individual researchers, universities, firms and the wider economy.

Continue support for open research data repositories. There is good evidence that they can support positive economic outcomes (although this varies from case to case). Evidencing effectiveness and impacts would be easier if more information were collected on users and uses to which data are put (especially commercial uses which currently leave few traces). This would also allow for better international comparison.

Continue research into new metrics and incentives. Work is ongoing to develop metrics which can more usefully capture the wider impacts of open science outputs. This could also include consideration of social metrics - for example, ways in which companies could indicate their use and/or approval of a dataset (similar to a 'like' on Facebook). This would act as a non-scholarly equivalent to the citation, and could provide a similar basis for research impact assessment.

Supplementary Materials: The REA protocol is available online at https://osf.io/jd3eb.

Funding: This review was conducted by the author while on secondment at the UK Department for Business, Energy and Industrial Strategy (BEIS). Further work to prepare it for publication was undertaken subsequently. The author is publishing it independently; it is not endorsed by BEIS, nor does it claim to represent their views.

Acknowledgments: I gratefully acknowledge the very useful feedback provided at various stages of this review by the following individuals: Sarah Ali-Khan; Rachel Bruce; Richard Gold; Steven Hill; Stephen Pinfield; Robin Simpson; and a number of individuals who remain anonymous. Any errors or omissions are entirely my own.

Conflicts of Interest: The author declares no conflict of interest.

\section{Appendix A}

Table A1. Summary of main aims and methods of the included studies.

\begin{tabular}{|c|l|}
\hline Ref & \multicolumn{1}{c|}{ Study Aims and Approach } \\
\hline \multirow{1}{*}[15]{} & $\begin{array}{l}\text { Beagrie, N. \& Houghton, J. The Value and Impact of Data Sharing and Curation: A synthesis of three recent studies of } \\
\text { UK research data centres. (Jisc, 2014). }\end{array}$ \\
\cline { 2 - 3 } & $\begin{array}{l}\text { A synthesis of three similar studies, the full report for each of which was also drawn on in this review [27,35,36]. They are } \\
\text { treated together here as they formed part of a programme of work with very similar aims and methods. } \\
\text { Aims: To identify the value for, and impacts on, users and depositors of three research data repositories: The Economic and } \\
\text { Social Data Service, the Archaeology Data Service, and the British Atmospheric Data Centre. } \\
\text { Methods: }\end{array}$ \\
$\begin{array}{l}\text { - Semi-structured interviews with a cross-section of stakeholders at each data service }(\mathrm{n}=13-25) . \\
\text { Online surveys with users (n = 299-141) and depositors (n = 42-193). } \\
\text { Macro-economic modelling based on Solow-Swan model exploring impact of increasing accessibility and efficiency of } \\
\text { research findings on return to research and development. } \\
\text { Calculation of investment value, contingent value (based on willingness-to-pay/accept), use value, welfare approaches } \\
\text { estimating consumer surplus and net economic value, and an activity costing approach to estimate efficiency savings. }\end{array}$ \\
\hline
\end{tabular}


Table A1. Cont.

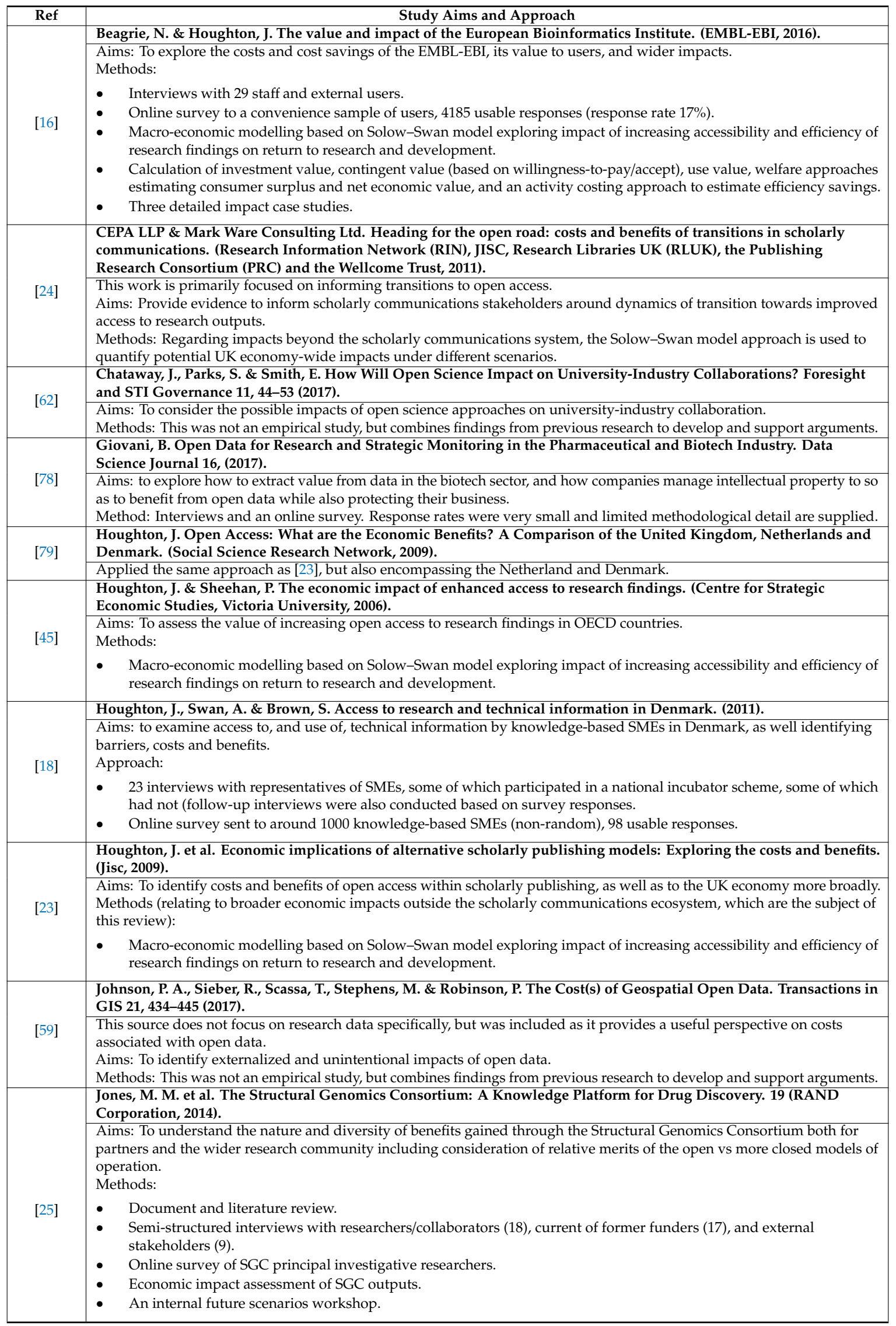


Table A1. Cont.

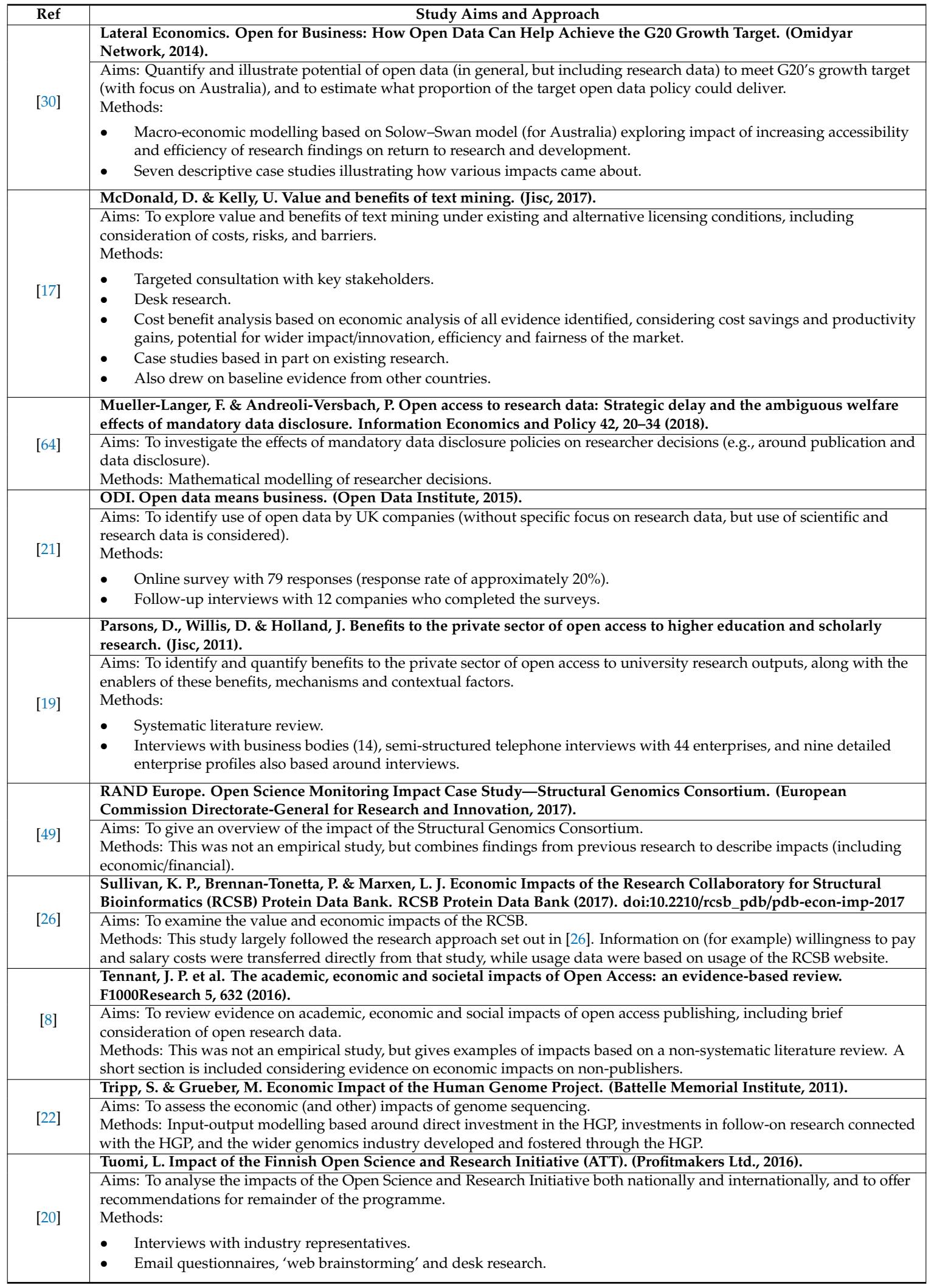




\section{Appendix B}

Table A2. Search strings used to identify material in online searches, the dates of searches, the number of records collected in each search, along with explanatory comments.

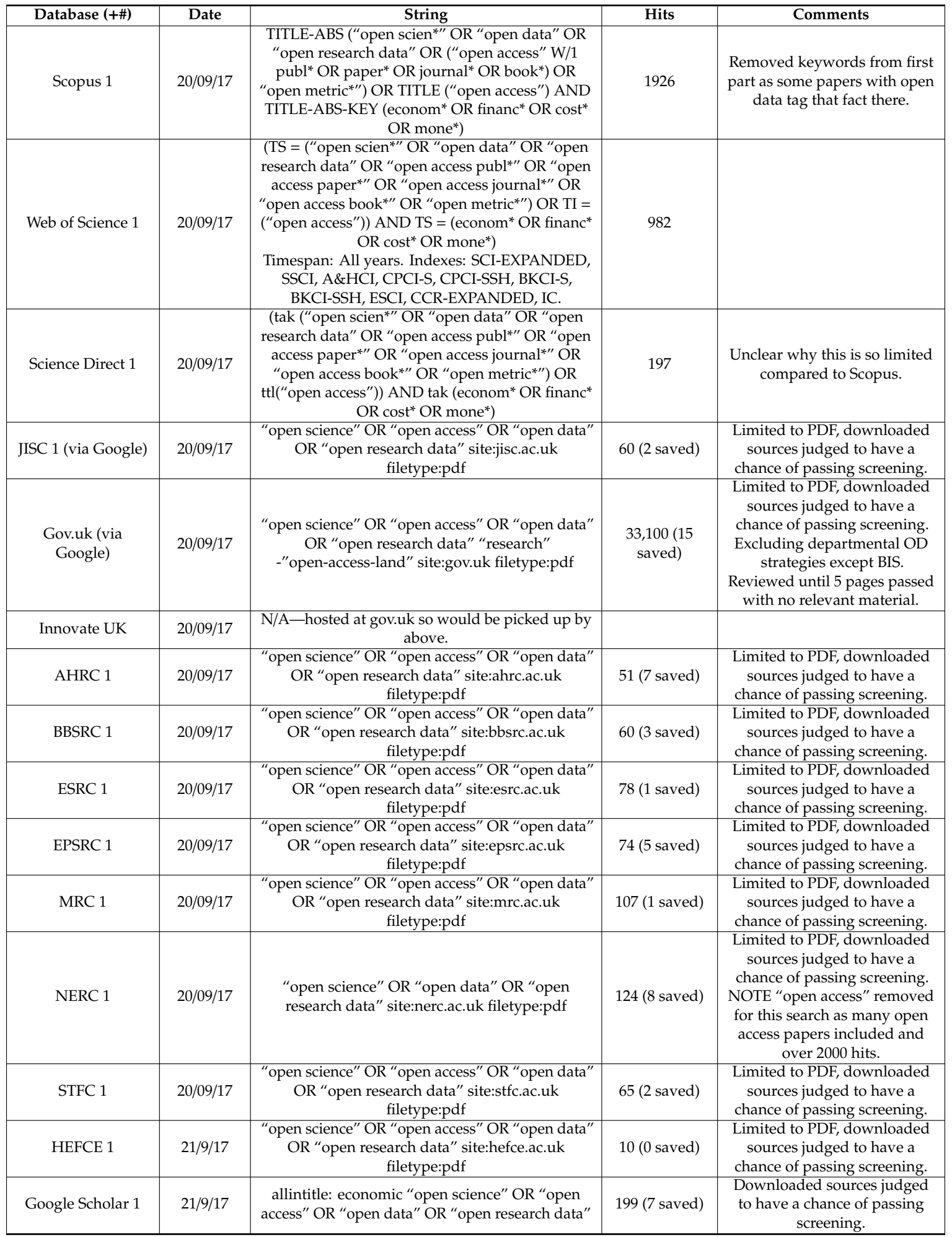


Table A2. Cont.

\begin{tabular}{|c|c|c|c|c|}
\hline Database (+\#) & Date & String & Hits & Comments \\
\hline Google Scholar 2 & 21/9/17 & $\begin{array}{l}\text { allintitle: impact "open science" OR "open data" } \\
\text { OR "open research data" }\end{array}$ & 90 (5 saved) & $\begin{array}{l}\text { Downloaded sources judged } \\
\text { to have a chance of passing } \\
\text { screening. Removed 'open } \\
\text { access' as many articles on } \\
\text { citation impact. }\end{array}$ \\
\hline ODI 1 & 21/9/17 & $\begin{array}{c}\text { "open science" OR "open access" OR "open data" } \\
\text { OR “open research data" site:theodi.org } \\
\text { filetype:pdf }\end{array}$ & 44 (0 saved) & $\begin{array}{l}\text { Downloaded sources judged } \\
\text { to have a chance of passing } \\
\text { screening. }\end{array}$ \\
\hline DCC 1 & 21/9/17 & $\begin{array}{c}\text { impact "open science" OR "open access" OR } \\
\text { "open data" OR "open research data" } \\
\text { site:dcc.ac.uk }\end{array}$ & 2480 (0 saved) & First 100 hits reviewed. \\
\hline Nesta 1 & $21 / 9 / 17$ & $\begin{array}{l}\text { "open science" OR "open access" OR "open data" } \\
\text { OR “open research data" site:nesta.org.uk } \\
\text { filetype:pdf }\end{array}$ & 143 (2 saved) & $\begin{array}{l}\text { Limited to PDF, downloaded } \\
\text { sources judged to have a } \\
\text { chance of passing screening. }\end{array}$ \\
\hline $\begin{array}{l}\text { Open Research } \\
\text { Funders Group } 1\end{array}$ & $21 / 9 / 17$ & $\begin{array}{c}\text { "open science" OR "open access" OR "open data" } \\
\text { OR "open research data" site:orfg.org }\end{array}$ & 5 (0 saved) & \\
\hline $\begin{array}{l}\text { Open Access } \\
\text { Bibliography } 1\end{array}$ & $21 / 9 / 17$ & & & $\begin{array}{c}\text { Scanned through bibliography, } \\
\text { more on impacts on } \\
\text { publishers/institutions. }\end{array}$ \\
\hline Universities UK 1 & 27/9/17 & $\begin{array}{c}\text { "open science" OR "open access" OR "open data" } \\
\text { OR "open research data" } \\
\text { site:universitiesuk.ac.uk filetype:pdf }\end{array}$ & 38 (1 saved) & $\begin{array}{l}\text { Limited to PDF, downloaded } \\
\text { sources judged to have a } \\
\text { chance of passing screening. }\end{array}$ \\
\hline Universities UK 2 & 27/9/17 & $\begin{array}{c}\text { impacts "open science" OR "open access" OR } \\
\text { "open data" OR "open research data" } \\
\text { site:universitiesuk.ac.uk }\end{array}$ & 29 (0 saved) & \\
\hline Europa.eu 2 & 27/9/17 & $\begin{array}{c}\text { impacts "open science" OR “open access" OR } \\
\text { "open data" OR “open research data" } \\
\text { site:europa.eu }\end{array}$ & $\begin{array}{l}49,000(12 \\
\text { saved })\end{array}$ & First 100 results reviewed. \\
\hline Europa.eu 3 & 27/9/17 & "open research data" site:europa.eu & 2800 (1 saved) & $\begin{array}{l}\text { Link saved is to EU Open } \\
\text { Research Data Pilot-to look } \\
\text { at in general. }\end{array}$ \\
\hline EUA 1 & 27/9/17 & $\begin{array}{l}\text { "open science" OR "open access" OR "open data" } \\
\text { OR "open research data" site:eua.be }\end{array}$ & 514 (0 saved) & $\begin{array}{l}\text { More on implications for } \\
\text { universities. }\end{array}$ \\
\hline Google 1 & 27/9/17 & $\begin{array}{l}\text { "economic impacts" “open science" OR "open } \\
\text { access" OR "open research data" filetype:pdf }\end{array}$ & $\begin{array}{l}81300(6 \\
\text { saved })\end{array}$ & $\begin{array}{c}\text { First } 80 \text { results reviewed (until } \\
\text { no relevant links for several } \\
\text { pages). }\end{array}$ \\
\hline Google 2 & 27/9/17 & $\begin{array}{l}\text { "economic impacts" "open science" OR "open } \\
\text { access" OR "open research data" }\end{array}$ & $184 \mathrm{k}$ (7 saved) & $\begin{array}{c}\text { First } 80 \text { results reviewed (until } \\
\text { no relevant links for several } \\
\text { pages). Did not download } \\
\text { some docs which were also } \\
\text { identified in other searches. }\end{array}$ \\
\hline Google 3 & 27/9/17 & $\begin{array}{c}\text { economic impacts "open science" OR "open } \\
\text { access" OR "open research data" }\end{array}$ & $59 \mathrm{~m}$ & $\begin{array}{l}\text { No additional useful docs } \\
\text { identified in first } 50 \text { results. }\end{array}$ \\
\hline Scopus 2 & 27/9/17 & $\begin{array}{l}\text { TITLE-ABS ("open scien*" OR “open data" OR } \\
\text { "open research data" OR ("open access" W/1 } \\
\text { publ* OR paper* OR journal* OR book*) OR } \\
\text { "open metric*") OR TITLE ("open access") AND } \\
\text { TITLE-ABS-KEY (cba OR bca OR “input-output" } \\
\text { OR "general equilibrium" OR "return on } \\
\text { investment" OR "growth accounting") }\end{array}$ & 21 & Terms suggested by reviewer. \\
\hline
\end{tabular}


Table A2. Cont.

\begin{tabular}{|c|c|c|c|c|}
\hline Database (+\#) & Date & String & Hits & Comments \\
\hline Scopus 4 & $13 / 4 / 19$ & 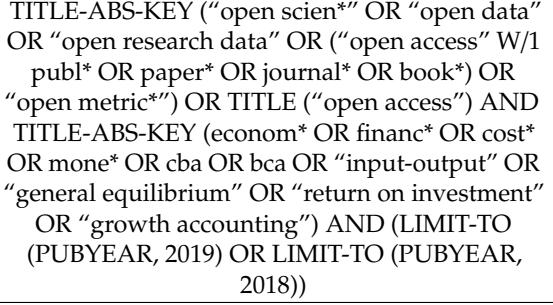 & 628 & $\begin{array}{c}\text { Update search. Items were } \\
\text { screened by title and abstract } \\
\text { in Scopus, and } 11 \text { which met } \\
\text { initial criteria were } \\
\text { downloaded. }\end{array}$ \\
\hline Google 4 & 13/4/19 & $\begin{array}{l}\text { "economic impacts" “open science" OR "open } \\
\text { research data" filetype:pdf }\end{array}$ & $\begin{array}{l}\text { No value } \\
\text { provided (3 } \\
\text { saved) }\end{array}$ & $\begin{array}{l}\text { Update search. Limited to } \\
2018 \text { onwards. First } 80 \text { results } \\
\text { reviewed (until no relevant } \\
\text { links for several pages). }\end{array}$ \\
\hline Google 5 & $13 / 4 / 19$ & $\begin{array}{c}\text { "economic impacts" “open science" OR “open } \\
\text { research data" }\end{array}$ & $\begin{array}{l}\text { No value } \\
\text { provided }(0 \\
\text { saved })\end{array}$ & $\begin{array}{c}\text { Update search. Limited to } \\
2018 \text { onwards. First } 80 \text { results } \\
\text { reviewed. }\end{array}$ \\
\hline
\end{tabular}

\section{References}

1. Research Councils UK. RCUK Policy on Open Access and Supporting Guidance. 2013. Available online: https://www.ukri.org/files/legacy/documents/rcukopenaccesspolicy-pdf/ (accessed on 27 June 2019).

2. Higher Education Funding Council for England; Research Councils UK; Universities UK. Wellcome Concordat on Open Research Data. 2016. Available online: https:/www.ukri.org/files/legacy/documents/ concordatonopenresearchdata-pdf/ (accessed on 27 June 2019).

3. European Open Science Cloud EOSC Declaration. 2017. Available online: https://ec.europa.eu/ (accessed on 27 June 2019).

4. European Commission Open Science Monitor. Available online: https://ec.europa.eu/info/researchand-innovation/strategy/goals-research-and-innovation-policy/open-science/open-science-monitor_en (accessed on 12 April 2019).

5. Doyle, M.F. H.R.3427-115th Congress (2017-2018): Fair Access to Science and Technology Research Act of 2017. Available online: https://www.congress.gov/bill/115th-congress/house-bill/3427 (accessed on 14 April 2019).

6. Elsabry, E. Claims about benefits of open access to society (Beyond Academia). Expand. Perspect. Open Sci. Commun. C. Diver. Concepts Pract. 2017, 34-43. [CrossRef]

7. ElSabry, E. Who needs access to research? Exploring the societal impact of open access. Rev. Fr. Sci. l'inform. Commun. 2017, 11. [CrossRef]

8. Tennant, J.P.; Waldner, F.; Jacques, D.C.; Masuzzo, P.; Collister, L.B.; Hartgerink, C.H. The academic, economic and societal impacts of Open Access: an evidence-based review. F1000Research 2016, 5, 632. [CrossRef] [PubMed]

9. OECD. Making Open Science a Reality; Organisation for Economic Co-Operation and Development: Paris, France, 2015.

10. Vicente-Saez, R.; Martinez-Fuentes, C. Open Science now: A systematic literature review for an integrated definition. J. Bus. Res. 2018, 88, 428-436. [CrossRef]

11. Wilson, S.; Sonderegger, S. Understanding the Behavioural Drivers of Organisational Decision-Making: Rapid Evidence Assessment; HM Government: London, UK, 2016.

12. RAND Europe. What Works in Changing Energy-Using Behaviours in the Home? A Rapid Evidence Assessment; Department of Energy and Climate Change: London, UK, 2012.

13. Liberati, A.; Altman, D.G.; Tetzlaff, J.; Mulrow, C.; Gøtzsche, P.C.; Ioannidis, J.P.A.; Clarke, M.; Devereaux, P.J.; Kleijnen, J.; Moher, D. The PRISMA statement for reporting systematic reviews and meta-analyses of studies that evaluate healthcare interventions: explanation and elaboration. BMJ 2009, 339, b2700. [CrossRef] [PubMed]

14. Haddaway, N.R.; Collins, A.M.; Coughlin, D.; Kirk, S. The Role of Google Scholar in Evidence Reviews and Its Applicability to Grey Literature Searching. PLoS ONE 2015, 10, e0138237. [CrossRef] [PubMed]

15. Beagrie, N.; Houghton, J. The Value and Impact of Data Sharing and Curation: A Synthesis of Three Recent Studies of UK Research Data Centres; JISC: London, UK, 2014. 
16. Beagrie, N.; Houghton, J. The Value and Impact of the European Bioinformatics Institute; EMBL-EBI: Cambridge, UK, 2016.

17. McDonald, D.; Kelly, U. Value and Benefits of Text Mining; JISC: London, UK, 2017.

18. Houghton, J.; Swan, A.; Brown, S. Access to Research and Technical Information in Denmark; University of Southampton Institutional Research Repository: Southampton, UK, 2011.

19. Parsons, D.; Willis, D.; Holland, J. Benefits to the Private Sector of Open Access to Higher Education and Scholarly Research; JISC: London, UK, 2011.

20. Tuomi, L. Impact of the Finnish Open Science and Research Initiative (ATT). 2016. Available online: http://www.doria.fi/handle/10024/127285 (accessed on 27 June 2019).

21. ODI. Open Data Means Business; Open Data Institute: London, UK, 2015.

22. Tripp, S.; Grueber, M. Economic Impact of the Human Genome Project; Battelle Memorial Institute: Columbus, OH, USA, 2011.

23. Houghton, J.; Rasmussen, B.; Sheehan, P.; Oppenheim, C.; Morris, A.; Creaser, C.; Greenwood, H.; Summers, M.; Gourlay, A. Economic Implications of Alternative Scholarly Publishing Models: Exploring the Costs and Benefits; JISC: London, UK, 2009.

24. CEPA LLP; Mark Ware Consulting Ltd. Heading for the Open Road: Costs and Benefits of Transitions in Scholarly Communications; Research Information Network (RIN), JISC, Research Libraries UK (RLUK), the Publishing Research Consortium (PRC) and the Wellcome Trust: London, UK, 2011.

25. Jones, M.M.; Castle-Clarke, S.; Brooker, D.; Nason, E.; Huzair, F.; Chataway, J. The Structural Genomics Consortium: A Knowledge Platform for Drug Discovery; RAND Corporation: Santa Monica, CA, USA, 2014; p. 19.

26. Sullivan, K.P.; Brennan-Tonetta, P.; Marxen, L.J. Economic Impacts of the Research Collaboratory for Structural Bioinformatics (RCSB) Protein Data Bank. RCSB Protein Data Bank 2017. [CrossRef]

27. Charlies Beagrie Ltd.; Centre for Strategic Economic Studies. Economic Impact Evaluation of the Economic and Social Data Service; Economic and Social Research Council: Swindon, UK, 2012.

28. Stuermer, M.; Dapp, M.M. Measuring the promise of open data: Development of the impact monitoring framework. In Proceedings of the 2016 Conference for E-Democracy and Open Government (CeDEM) 2016, Krems, Austria, 18-20 May 2016; pp. 197-203.

29. Manyika, J.; Chui, M.; Groves, P.; Farrell, D.; van Kuiken, S.; Almasi Doshi, E. Open Data: Unlocking Innovation and Performance with Liquid Information; McKinsey: New York, NY, USA, 2013.

30. Lateral Economics. Open for Business: How Open Data Can Help Achieve the G20 Growth Target; Omidyar Network: Redwood City, CA, USA, 2014.

31. Research Information Network; Publishing Research Consortium; JISC. Access to Scholarly Content: Gaps and Barriers; JISC: London, UK, 2011.

32. Davis, P. Challenging Assumptions on Open Access Cost Savings. Available online: https://scholarlykitchen. sspnet.org/2009/07/16/challenging-assumptions-on-open-access-cost-savings/ (accessed on 12 April 2019).

33. McCulloch, A. Discussion on JISC Report on Economic Implications of Alternative Business Models. 2009. Available online: https://blog.alpsp.org/2009/02/discussion-on-jisc-report-on-economic.html (accessed on 27 June 2019).

34. Jubb, M.; Plume, A.; Oeben, S.; Brammer, L.; Johnson, R.; Butun, C.; Pinfield, S. Monitoring the Transition to Open Access; Universities UK: London, UK, 2017.

35. Beagrie, N.; Houghton, J. The Value and Impact of the Archaeology Data Service: A Study and Methods for Enhancing Sustainability; Charles Beagrie Ltd.: Salisbury, UK, 2013.

36. Beagrie, N.; Houghton, J. The Value and Impact of the British Atmospheric Data Centre; JISC: London, UK, 2013.

37. Breidert, C.; Hahsler, M.; Reutterer, T. A Review of Methods for Measuring Willingness-to-Pay. Innov. Mark. 2006, 2, 8-32.

38. Lee, W.H. Open access target validation is a more efficient way to accelerate drug discovery. PLoS Biol. 2015, 13, e1002164. [CrossRef]

39. JISC The Text and Data Mining Copyright Exception: Benefits and Implications for UK Higher Education. Available online: https://www.jisc.ac.uk/guides/text-and-data-mining-copyright-exception (accessed on 12 April 2019).

40. LIBER Copyright Reform: Help us Ensure an Effective TDM Exception! LIBER: The Hague, The Netherlands, 2017. 
41. Leeson, P.D.; St-Gallay, S.A. The influence of the "organizational factor" on compound quality in drug discovery. Nat. Rev. Drug Discov. 2011, 10, 749-765. [CrossRef]

42. Savage, N. Competition: Unlikely partnerships. Nature 2016, 533, S56-S58. [CrossRef] [PubMed]

43. Chalmers, I.; Glasziou, P. Avoidable waste in the production and reporting of research evidence. Lancet 2009, 374, 86-89. [CrossRef]

44. Bloom, N.; Jones, C.I.; Van Reenen, J.; Webb, M. Are Ideas Getting Harder to Find? National Bureau of Economic Research: Cambridge, MA, USA, 2017.

45. Houghton, J.; Sheehan, P. The Economic Impact of Enhanced Access to Research Findings; Centre for Strategic Economic Studies, Victoria University: Melbourne, Australia, 2006.

46. SPARC From Ideas to Industries: Human Genome Project. Available online: https://sparcopen.org/impactstory/human-genome-project/ (accessed on 12 April 2019).

47. Williams, H.L. Intellectual Property Rights and Innovation: Evidence from the Human Genome. J. Polit. Econ. 2013, 121, 27. [CrossRef]

48. Structural Genomics Consortium Mission and Philosophy. Available online: https://www.thesgc.org/about/ what_is_the_sgc (accessed on 12 April 2019).

49. RAND Europe. Open Science Monitoring Impact Case Study-Structural Genomics Consortium; European Commission Directorate-General for Research and Innovation: Brussel, Belgium, 2017.

50. Arshad, Z.; Smith, J.; Roberts, M.; Lee, W.H.; Davies, B.; Bure, K.; Hollander, G.A.; Dopson, S.; Bountra, C.; Brindley, D. Open access could transform drug discovery: A case study of JQ1. Expert Opin. Drug Discov. 2016, 11, 321-332. [CrossRef] [PubMed]

51. Tensha Therapeutics Tensha Therapeutics to Be Acquired by Roche. Available online: https:// www.businesswire.com/news/home/20160111005488/en/Tensha-Therapeutics-Acquired-Roche (accessed on 12 April 2019).

52. Perkmann, M.; Schildt, H. Open data partnerships between firms and universities: The role of boundary organizations. Res. Policy 2015, 44, 1133-1143. [CrossRef]

53. Structural Genomics Consortium International Structural Genomics Consortium Announces $\$ 48.9$ MILLION in Additional Funding to Continue the Search for New Medicines 2011. Available online: https://www.pfizer. com/sites/default/files/partnering/092811_international_structural_genomics_consortium.pdf (accessed on 12 April 2019).

54. Montreal Neurological Institute and Hospital Open Science. Available online: https://www.mcgill.ca/neuro/ open-science-0 (accessed on 12 April 2019).

55. Montreal Neurological Institute and Hospital Measuring the Impact of Open Science. Available online: https://www.mcgill.ca/neuro/open-science-0/measuring-impact-open-science (accessed on 12 April 2019).

56. SPOMAN Open Science About OS|Spoman OS. Available online: https://spoman-os.org/about-os/ (accessed on 12 April 2019).

57. Weeber, M.; Vos, R.; Klein, H.; de Jong-van den Berg, L.T.W.; Aronson, A.R.; Molema, G. Generating Hypotheses by Discovering Implicit Associations in the Literature: A Case Report of a Search for New Potential Therapeutic Uses for Thalidomide. J. Am. Med. Inform. Assoc. 2003, 10, 252-259. [CrossRef] [PubMed]

58. Houghton, J.; Sheehan, P. Estimating the Potential Impacts of Open Access to Research Findings. Econ. Anal. Policy 2009, 39, 127-142. [CrossRef]

59. Johnson, P.A.; Sieber, R.; Scassa, T.; Stephens, M.; Robinson, P. The Cost(s) of Geospatial Open Data. Trans. GIS 2017, 21, 434-445. [CrossRef]

60. Huber, F.; Wainwright, T.; Rentocchini, F. Open data for open innovation: managing absorptive capacity in SMEs. RED Manag. 2018. [CrossRef]

61. Morgan, M.R.; Roberts, O.G.; Edwards, A.M. Ideation and implementation of an open science drug discovery business model-M4K Pharma. Welcome Open Res. 2018, 3, 154. [CrossRef]

62. Chataway, J.; Parks, S.; Smith, E. How Will Open Science Impact on University-Industry Collaboration? Foresight STI Gov. 2017, 11, 44-53. [CrossRef]

63. European Commission. Validation of the Results of the Public Consultation on Science 2.0: Science in Transition; European Commission: Brussels, Belgium, 2015.

64. Mueller-Langer, F.; Andreoli-Versbach, P. Open access to research data: Strategic delay and the ambiguous welfare effects of mandatory data disclosure. Inf. Econ. Policy 2017, 42, 20-34. [CrossRef] 
65. Caulfield, T.; Harmon, S.H.; Joly, Y. Open science versus commercialization: a modern research conflict? Genome Med. 2012, 4, 17. [CrossRef] [PubMed]

66. De Vrueh, R.L.A.; Crommelin, D.J.A. Reflections on the Future of Pharmaceutical Public-Private Partnerships: From Input to Impact. Pharm. Res. 2017, 34, 1985-1999. [CrossRef] [PubMed]

67. Mark Ware Consulting Ltd. Access by UK Small and Medium-Sized Enterprises to Professional and Academic Information; Publishing Research Consortium: Hamburg, Germany, 2009.

68. Vines, T. Is There a Business Case for Open Data? Available online: https://scholarlykitchen.sspnet.org/2017/ 11/15/business-case-open-data/ (accessed on 12 April 2019).

69. Bilder, G. Crossref's DOI Event Tracker Pilot. Available online: https://www.crossref.org/blog/crossrefs-doievent-tracker-pilot/ (accessed on 12 April 2019).

70. Mowery, D.C.; Ziedonis, A.A. Markets versus spillovers in outflows of university research. Res. Policy 2015, 44, 50-66. [CrossRef]

71. Fukugawa, N. Knowledge spillover from university research before the national innovation system reform in Japan: localisation, mechanisms, and intermediaries. Asian J. Technol. Innov. 2016, 24, 100-122. [CrossRef]

72. Keseru, J. A New Approach to Measuring the Impact of Open Data. Available online: https://sunlightfoundation. com/2015/05/05/a-new-approach-to-measuring-the-impact-of-open-data/ (accessed on 12 April 2019).

73. Publication Bias in Meta-Analysis: Prevention, Assessment and Adjustments; Rothstein, H.; Sutton, A.J.; Borenstein, M. (Eds.) Wiley: Chichester, UK; Hoboken, NJ, USA, 2005; ISBN 978-0-470-87014-3.

74. Gold, E.R.; Ali-Khan, S.E.; Allen, L.; Ballell, L.; Barral-Netto, M.; Carr, D.; Chalaud, D.; Chaplin, S.; Clancy, M.S.; Clarke, P.; et al. An open toolkit for tracking open science partnership implementation and impact. Gates Open Res. 2019, 3, 1442. [CrossRef]

75. OpenMinted About. OpenMinTeD. 2015. Available online: http://openminted.eu/omtd-publications/ (accessed on 27 June 2019).

76. Konfer About Konfer. Available online: https://www.konfer.online/media (accessed on 12 April 2019).

77. Bishop Grosseteste University About LORIC_BGU. Available online: https://www.bishopg.ac.uk/loric/ about-loric/ (accessed on 27 June 2019).

78. Giovani, B. Open data for research and strategic monitoring in the pharmaceutical and biotech industry. Data Sci. J. 2017, 16. [CrossRef]

79. Houghton, J. Open Access: What are the Economic Benefits? A Comparison of the United Kingdom, Netherlands and Denmark; Social Science Research Network: Rochester, NY, USA, 2009. 